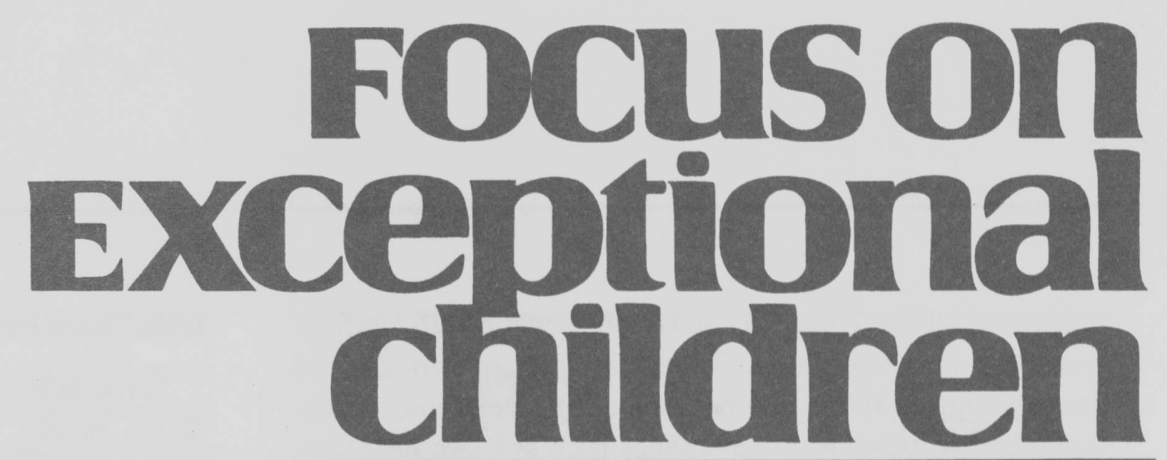

\title{
Adapted Physical Education: Self-Control and Attention
}

\author{
Bryant J. Cratty
}

The most pervasive characteristics of populations of children and youth with special needs are distractibility, lack of self-control, and poor attention. Typically these problems occur because the individual is overactivated or too excited to function normally, or underactivated or too "dreamy" to pay proper attention to important parts of the environment. These problems can be manifested in (a) poor assimilation of a lesson, (b) social abrasiveness and aggression toward peers, parents, and teachers, and (c) physical danger to the child or youth himself or herself.

Over the years many professionals have suspected that hyperactivity and inattention have a familial basis. Data from a recent study suggest that hyperactive children may or may not have family members who are similarly afflicted (August \& Stewart, 1983). These same investigators found that a child, one of whose parents may have been hyperactive, is likely to display a greater variety of behavioral disturbances than a child whose family members are free of hyperactive tendencies. Usually, hyperactivity in a child is caused by organic (neurological) problems combined with environmental and social-emotional factors. Educators promoting physical activity have a special obligation to understand the root causes of distractible behaviors and provide techniques and methods by which these undesirable aspects of behavior may be adjusted in positive ways. A useful tool has been developed by Torrey (1981) to help parents and others identify hyperactive-hypertensive children in need of various kinds of intervention. This Hyperactivity Behaviors Identification Questionnaire is beginning to be used in various research studies (Brandon, Eason, \& Smith, 1986). The questionnaire asks the rater to rank a child on a 5-point scale ranging from 5 (always) through 3 (sometimes) to 1 (never). Thirteen statements are rated in this manner. For example: "My child gets into things" ... "My child is easily upset" . . "My child is impatient."

For several decades various medications (usually stimulant drugs) have been used in efforts to reduce hyperactive/inattentive behaviors. For the most part, however, medications have not significantly improved test scores, they produce highly variable individual

Bryant J. Cratty is professor emeritus and was director of the Perceptual-Motor Learning Laboratory, University of California, Los Angeles. He has authored 32 books and numerous research articles dealing with adapted physical education. This article is adapted from Adapted Physical Education in the Mainstream (2nd edition) published by Love Publishing Company. 
reactions, and they may not have long-term positive effects extending into adulthood. Recent reviews of this kind of therapy suggest that some behavioral interventions, including cognitive-behavioral techniques such as those described here, are superior (Gadow, 1983).

In the last several decades, methods of activation adjustment have involved changing physiological behaviors (muscular relaxation, deep breathing, and the like), imagery (e.g., "Imagine yourself by a quiet stream"), and, more recently, helping people to think differently and thus aid in self-control (e.g., "Tell me how you should plan this lesson before starting it"). Some of these methods have been inspired by mystical-religious strategies dating back for centuries; others are the product of modern psychologists who are interested in cognitive adjustment. Physical education teachers who can call upon several of these techniques when appropriate can be far more effective than those who cannot or will not. And children and youth who learn and are able to apply methods of self-control often acquire heightened feelings of self-worth and self-effectiveness (Meichenbaum \& Goodman, 1969).

\section{FOCuson
Exceptional children}

ISSN 0015-511X FOCUS ON EXCEPTIONAL CHILDREN (USPS 203-360) is published monthly except June, July, and August as a service to teachers, special educators, curriculum specialists, administrators, and those concerned with the special education of exceptional children. This publication is annotated and indexed by the ERIC Clearinghouse on Handicapped and Gifted Children for publication in the monthly Current Index to Journals in Education (CIJE) and the quarterly index, Exceptional Children Education Resources (ECER). The full text of Focus on Exceptional Children is also available in the electronic versions of the Education Index. It is also available in microfilm from Xerox University Microfilms, Ann Arbor, MI. Subscription rates: individual, \$36 per year; institutions, $\$ 48$ per year. Copyright (C) 2004, Love Publishing Company. All rights reserved. Reproduction in whole or part without written permission is prohibited. Printed in the United States of America. Periodical postage is paid at Denver, Colorado. POSTMASTER: Send address changes to:

Love Publishing Company

Executive and Editorial Office P.O. Box 22353

Denver, Colorado 80222

Telephone (303) 221-7333

Susan T. Warhover Editor
Stanley F. Love

Publisher

\section{DIMENSIONS OF THE PROBLEM}

Hyperactivity and lack of attentiveness have numerous facets. Indeed, a case may be made that hyperactivity is in the eye of the beholder! Hyperactive children at times have been found objectively to be no more active than students judged "good" by their teachers; their movements simply occur at socially inappropriate times.

With that note of caution, hyperactivity may be classified into at least three broad categories: (a) visual hyperactivity - displayed by children whose bodies remain in place (in their classroom seats) but whose eyes dart from place to place; (b) bodily hyperactivity - demonstrated by children who do not remain in one place and are seldom in their seats or in proper positions for participation in planned activities; and (c) manipulative hyperactivityexhibited by children whose hands are constantly moving although the body remains relatively fixed. Of course, some individuals evidence all of these behaviors in various combinations.

Theories and models that try to explain hyperactive behavior abound. These generally focus on any of three sets of variables: (a) neurological health of the individual, or causes arising within the person; (b) behavioral makeup of the person together with the make-up of the social environment in which the person must function; and (c) learning-teaching environment. To some extent, the acceptance of a given model or theory-particularly as it relates to a specific child or youth - tends to guide remedial strategies.

For example, an explanation or diagnosis of a child as having a neurological problem (usually related to brain stem function) may prompt the prescription of a medication to correct the problem. On the other hand, a more environmental or behavioral orientation toward a given youngster's distractibility encourages the use of psychotherapy coupled with adjustment of learning and social variables.

Finally, hyperactivity and related attentional disorders sometimes are situational. A child may have relatively controlled behavior in one setting (in the home, while watching TV) while at school he or she may be judged as highly impulsive and difficult to teach. Therefore, a thorough diagnosis of a so-called hyperactive child should involve assessments of that child in a number of the life settings in which he or she must function.

\section{PRINCIPLES, GUIDELINES, AND TECHNIQUES}

The remainder of this article contains straightforward techniques that have been found useful in reducing hyperactivity and improving attention and self-control, with emphasis on the principles and general guidelines underlying 
them. No hyperactive child is like another; most have unique problems. Therefore, professionals involved with the child should work closely as a team and should apply individually designed programs to a given child or youth. The interventions covered here are limited to those appropriately applied by a physical educator. Although medication, diet control, and other strategies often are used in conjunction with the movement strategies to be discussed, the former should be supervised by professionals who are competent in their use.

\section{Muscular Relaxation}

Edmund Jacobson (1938) has been credited with introducing techniques involving muscular relaxation in the English language texts more than 50 years ago. This approach is based on two major premises:

1. Individuals can learn, usually with the help of others at first, to adjust muscular tension.

2. The control or reduction of excess muscular tension is likely to produce parallel and positive adjustments of an individual's emotional state.

Typically a session involves talking an overly tense individual through successive stages of relaxation, together with imagery that is likely to induce better perceptions of excess tension and of consecutive stages in relaxation. Capable, mature persons often can adopt the technique after a few sessions. With other individuals, however, the program is supervised by a therapist or instructor. Effective relaxation specialists are able to conjure up effective relaxation imagery through appropriate words and phrases. The following lesson might take place after the youngster has been placed in a comfortable position, as seen in Figure 1.

First, see how hard you can tighten the muscles in your face by closing your eyes tightly and tightening the muscles of your cheeks. ... Now try to relax these same muscles completely-first the muscles of your forehead ... now those around your mouth . . . and now the jaw muscles and cheek muscles.

Now let's move down your body and do the same thing with the muscles in the front of your neck. Pull your chin down toward your chest, and tighten the muscles in your neck . . . harder. . . . Now relax your neck completely, and slowly move your head up and down to see if you have done so. (Often the teacher/therapist will move the person's limbs and other body parts to see if tension and then relaxation have been consecutively achieved.)

Now let's go further down your body and tighten the muscles in the front of your chest as hard as you can. Roll your shoulders slightly inward to do this. Now take a deep breath and relax your chest muscles

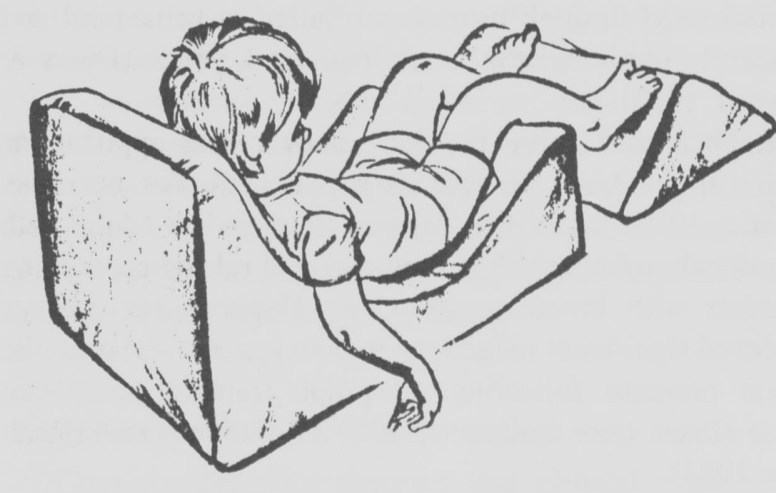

FIGURE 1

A Position Conducive to Relaxation Training

completely ... more ... more. ... Take another breath and let it out.

Next we will work on your arms. Tighten your arms to your side and make hard balls of your fists. . . Now release your hands, relax them in an extended position, and try to relax your arms and shoulders completely.

The stomach muscles might be alternately tightened and relaxed in the same way. Then the therapist/teacher might proceed downward to the hips, leg, and feet muscles and work up again from the feet to the head and face. During successive sessions, finer and finer discriminations of muscle tension might be promoted. For example: "Now you have tightened your muscle as hard as you can. See if you can tighten it half that hard ... now half-again as hard as you did last time."

Relaxation training often is accompanied by visual imagery and helpful breathing exercises. For example: "Imagine yourself beside a quiet stream as you lie there relaxing." Tightening muscles often is paired with breath holding. Relaxation may be heightened if the student attempts to exhale completely or to breathe rhythmically with complete inhalation and exhalation.

Jacobson's traditional methods are constantly being refined and improved. For example, Herson and Barlow (1976) have developed a technique they have labeled behavioral relaxation training (BRT). It involves directing training in 10 postures that have been found to be maximally relaxing, based upon electromyographic verification. This method has been used in several recent studies (Brandon, Eason, \& Smith, 1986; Poppen \& Maurer, 1982; Schilling \& Poppen, 1983) with both adult and child subjects, achieving positive results. And Jacobson also applied his techniques to 
children (Jacobson, 1973). At times relaxation training administered through tapes has resulted in behavioral and academic improvement in children and youth (Dunn \& Howell, 1982).

Relaxation training has had many recent applications with various kinds of special populations. For example, Glantz (1983) found that reading improved in adults with emotional problems when they received relaxation training together with breathing exercises. Hypertensive patients achieved significant reductions in both systolic and diastolic blood pressure following relaxation training; moreover, these effects were maintained after a 5-month period (Wadden, 1983).

In another study (Rickard, Thrasher, \& Elkins, 1984), individuals within four IQ ranges were found to benefit from several types of relaxation training, including those involving imagery as well as suggestions to relax and to control breathing. Even the individuals in the lower functioning groups seemed to comprehend the instructions and benefit from the training. Brandon and his colleagues (Brandon et al., 1986) found that relaxation training improved the ability of males who were learning disabled to attend to a "demanding motor task." Relaxation training also has been shown to be effective in handwriting training, auditory memory, spelling, and oral reading (Carter, Lax, \& Russell, 1979; Carter \& Russell, 1980; Carter \& Synolds, 1974).

Relaxation training has several advantages - and a few cautions. Advantages include the fact that it is easily applied, with a minimum of space, time, and expense. Emotionally "high" children may be aided by reducing muscular tension, leading to reduced emotional tension.

Two major cautions are as follows: (a) At times children may be brought too far "down" and rendered too lethargic for subsequent participation (in a demonstration in Spain, a "helpful" volunteer put six children so far "under" that they could be awakened only with great effort and care on the part of onlookers!) and (b) the methodology may not work equally well with all people. Individuals have unique patterns of muscular tension that, while consistent within that person, vary greatly from person to person. Some children and adults have activated emotional states that are not accompanied by any discernible muscular tension. Thus, even though the techniques are practiced over time, positive results may not be obtained with all individuals.

Nevertheless, this method, and variations thereof, is potentially beneficial in arousal adjustment. Medication, if recommended by educationally sophisticated physicians, may be a helpful adjunct. When applied optimally, success in using this approach is probable over time.

In the early 1980s Schilling and Poppen (1983) developed a useful behavioral relaxation scale composed of 10 behaviors that purportedly reflect a state of relaxation, including "(a) body - no movement of the body trunk, (b) mouth-lips-slightly parted at the center of the mouth, (c) feet-pointed away from each other." In general these observational signposts correlate rather well with electromyographic evidence of relaxation (Poppen \& Maurer, 1982).

\section{Impulse-Control Activities}

Activities that encourage slow, controlled actions may be useful in adjusting tendencies to move too much, to move inappropriately, or to exhibit poor attention span. Historically, impulse-control exercises have been a part of oriental cultures, where they continue today. Middle-aged and elderly Chinese people often begin their day with Tai Chi. ${ }^{1}$

Two simpler impulse-control games are explained here. Both involve using a well-controlled peer as a model with whom the less-controlled (hyperactive) child may identify by imitating well-controlled movements. In one the hyperactive child is a closely following "shadow" to the model. In the second a tactile tracking game is employed, in which the hyperactive child replicates slow and fast movements of the model. Prolonged walking tasks like that illustrated in Figure 2 likewise may lengthen the attention span.

These activities also may be used as evaluative tools, because rather precise scores may be obtained from requests such as "Draw a line as slowly as you can" or perhaps "Stand up (from a back-lying position) as slowly as you can." Furthermore, controlled movements of this kind may be encouraged by having students compete in tasks to determine which of them can finish last in activities such as line walking, slow drawing, and arising. These impulsecontrol activities may be reinforced by external rewards in programs of traditional behavior modification. Moreover, their use with techniques of muscular relaxation often is useful.

As the child gains control in these actions, results may be determined by, for example, first asking a child to move slowly and then activating the child ("Let's see how fast you can run in place!"). This activation period can be followed by tasks that determine whether the child can again place himself or herself under control.

Research that I and others have conducted indicates that these actions correlate moderately to highly with test-taking attention and with teachers' ratings of self-control in classrooms. Recent data further indicate that the ability (or

IPositive physiological effects presented in research studies discussed at the International Congress of Sports Medicine in Beijing in 1985 include delays in deterioration of bones, as well as heightened flexibility. 


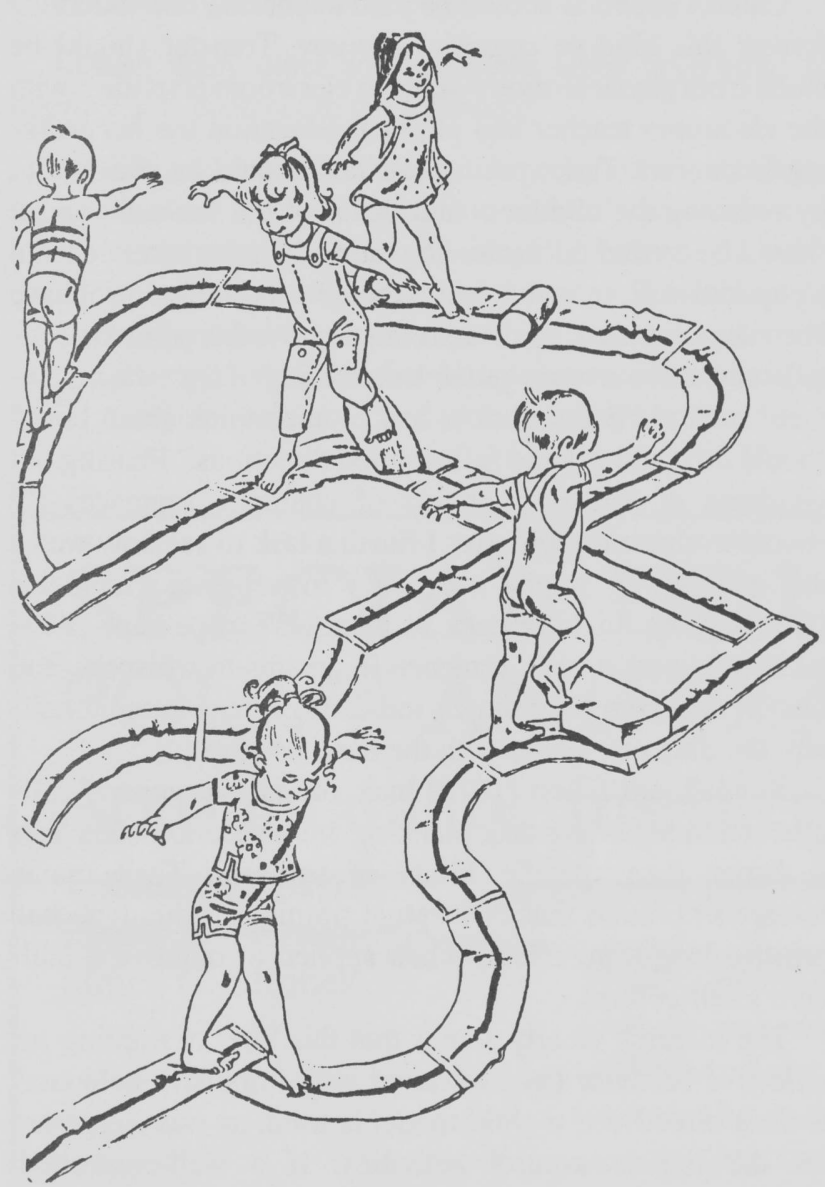

FIGURE 2

Prolonged Walking Tasks to Lengthen Attention Span

inclination) to move slowly when asked to do so may be somewhat specific to the action requested. Thus, a training program should include a variety of tasks rather than focusing on one or two "slow-moving" techniques (Savelli, Cratty, \& Pistoletti, 1985; Setterlind, 1985).

This kind of activity may be combined with tasks that require "held positions," as in typical yoga programs. Modifications of yoga have been found to be useful with special children, particularly those with excess tension and muscular and behavioral inflexibility. Classroom teachers and physical educators alike have used yoga successfully with various disability groups. If extreme positions are required and the yoga program is rigorous, however, the advice of physicians and therapists is essential.

As is true with muscular relaxation techniques, impulsecontrol activities are successful to the degree to which the actions are incorporated in imagery and language palatable to immature persons. These types of actions often are best incorporated into "sensory-motor stories" in which characters' movements portray emotions and story content. Impulse-control activities may be used with individuals who have minimal expressive language, although receptive language (understanding verbal directions) is needed. For the most part, the next group of techniques requires at least minimal expressive language skills.

\section{Cognitive-Behavioral Therapy}

Cognitive-behavior theories and clinical models first appeared in the literature during the 1950s. During the 1970s their popularity and acceptance soared as more and more data emerged substantiating their worth. With this expansion of research came useful and precise ways in which this kind of therapy might be applied to groups as diverse as alcoholics, depressives, psychotics-and hyperactive children and youth with learning disabilities. Selfmonitoring (self-talk) techniques aimed at improving hyperactive/distractible classroom behavior in students with learning disabilities have had positive results, for the most part (Hallahan \& Sapona, 1983). This suggests that physical educators might take advantage of modern metacognitive strategies.

The rationale underlying this general approach is based upon the assumption that our behaviors and emotions do not emerge in unexplained reflexive ways but, rather, are controllable and guided by our thoughts. Acceptance of this idea further suggests that changes in behaviors and feelings may be elicited by helping people change how they think about events, others, themselves, and their work, as well as about emotions and thoughts themselves. Children who lack attentional skills, who "barge into" tasks without reflecting, are exhibiting poor intellectual skills surrounding task performance, including skills needed to plan approaches to tasks, thoughts that may accompany task execution, and thoughts present upon completion of school tasks. It follows that improvement in task performance will come about when children are helped to change how they think about tasks.

The main tool of cognitive therapists is called self-talk. It is hypothesized that the ways in which children talk to themselves (or fail to self-instruct) influence subsequent performance and, if improved, reflect improvement in school performance. A teacher applying this approach will in specific ways tell an impulsive child what to say before, during, and after assigned tasks. With repeated efforts it is assumed that the child will internalize (believe, or evidence a "cognitive click") and thus accept the valid pairing of improved self-talk 
and the thoughts it represents with changes in school-task effort and result. The scenario for such a lesson might be as follows:

Teacher/Therapist: Before you do this task, I want you to say, "I must think very carefully about the directions given to me." Now please say it.

Child: I must think about the directions given to me.

Teacher/Therapist: Now say, "I must remember what I am told and arrange my work carefully," okay?

Child: I must remember what I am told and arrange my work carefully.

At this point, during these pre-task self-instructions (selftalk), even more task-specific directions might be encouraged-for example, "I must place my pencil at the proper starting point and hold the paper with the other hand."

Next come self-instructions appropriate during the task:

Teacher/Therapist: Now say, "While I do the task, I must watch carefully and avoid mistakes."

Child: While I do the task, I must watch carefully and avoid mistakes.

At this point the teacher/therapist might ask for self-talk . that is specific to the kind of mistake the child might make in the task performed (e.g., "I should try to stay between the lines").

Finally the teacher/therapist should require self-talk appropriate after the task is completed. This talk may include phrases reflecting self-evaluation, rewarding statements, and information useful in the next try at the task. During this post-task phase the self-talk might consist of the following:

Teacher/Therapist: Now say, "I made only a few mistakes. I did pretty well. Next time I will try harder to stay between the lines during the hard part of the maze."

Child: I made only a few mistakes. I did pretty well. Next time I will try harder to stay between the lines during the hard part of the maze."

Various motor skills can be combined with this kind of training in appropriate self-talk. Physical tasks are useful in this context because they often take some time to complete and thus permit accompanying self-talk. Also, the relative success or failure (or score) of a physical task usually is apparent to both the learner and the teacher.
Careful attention should be paid to phasing out and transferring this kind of cognitive therapy. Transfer should be made from physical-motor skills to classroom activities, with the classroom teacher and physical education teacher working in concert. Task-specific self-talk should be phased out by reducing the vividness and detail of the self-talk, and it should be carried out by having the child move directly from a physical skill, in which better thought and self-control have been demonstrated, to a classroom task. At this point the selftalk may become more general, consisting of a pre-task statement such as "Before I do a task, I must think about how I should do it and get and follow good directions." Phasing out vividness of self-talk consists of changing sentences ("I should evaluate myself after I finish a task to see how well I did and how I might improve") to sentence fragments ("Improve by thinking back to mistakes" or perhaps "Mistakes help next time"), sentence fragments to whispers, and finally, whispers to gestures indicating silent internal selftalk (holding one's chin with the hand pensively).

Kendall and Finch (1979) have found that general selfinstruction regarding task planning and execution behaviors is better than specific kinds of self-talk. These same researchers found that conceptual training of this type had positive long-term effects when applied to improving children's self-control.

The research clearly shows that this kind of training for reflective behavior (as contrasted with impulsive behavior) is most effective if a child model is used, as was suggested for the impulse-control activities. If a well-controlled, thoughtful child is employed as a model, the child with low attention will improve more than if instructions and training pass directly from the teacher/therapist to the problem child without the mediating child model.

Cognitive-behavioral applications are most useful in relatively verbal children with attentional problems and concomitant learning disabilities. Extremely low functioning persons - those with obvious central nervous system deficiencies-are less likely to improve.

Training in self-talk is a positive improvement over simply teaching a child to relax or to move slowly. Becoming less muscularly tense or moving slowly in themselves are not components of academic learning. But organizing one's thoughts before, during, and after task performance is important to learning. Cognitive-behavioral therapy attempts to help children think about their thinking, or what is termed meta-cognition. Tasks in physical education programs can be either starting points or ending points in improving self-control. That is, the physical education teacher may use this approach to improve attention to the physical tasks in his or her program or use the physical education tasks and program to elicit higher levels of attention in the academic classroom. 


\section{OTHER CONSIDERATIONS}

Among many other considerations when attempting to improve self-control are the following:

1. The physical education teacher may be asked to help transmit information about a child's behavior to a doctor who is medicating the child. Indeed, if a medicated child evidences either undue drowsiness or exaggerated hyperactivity while on medication, the physical educator should inform those medicating the youngster, even if it is not requested.
2. The physical education program may be arranged so that the child's attention is better focused, by decreasing the size of the group (and thus the number of potentially distracting classmates). The size and complexity (stimulation) of the area devoted to physical education may be adjusted. The room might be partitioned and made smaller, and extraneous noise and decorations could be reduced to heighten students' attention.

3. Children may be encouraged to utilize the methods explained in this article themselves, within their

\section{SPECIAL EDUCATION POLICY AND PRACTICE}

\section{Accountability, Instruction, and Social Challenges}

Thomas M. Skrtic

Karen R. Harris

James G. Shriner

This is an excellent book that addresses the policy shift in special education from procedural compliance to standards-based accountability and the changing conditions of practice under reform. It covers the major problems of implementing reform and presents several practices and models to improve the conditions of special education practice.

The authors support a collaborative environment for service delivery and inclusive work atmospheres with research-based instructional practices. The book gives prevention and intervention strategies including specific reading, writing, and mathematics instructional techniques. Other topics include transition, selfdetermination, school violence, health needs, and literacy instruction for Latino students.

The focus in the last part of the book is oriented to human needs and opportunities that will shape special education practice in the future including individual and environmental conditions. These include welfare of children working across social contexts and providing a planning framework for achieving integrated services:

0401 / Paperback / 582 pages / ISBN 0-89108-310-3 / \$68.00

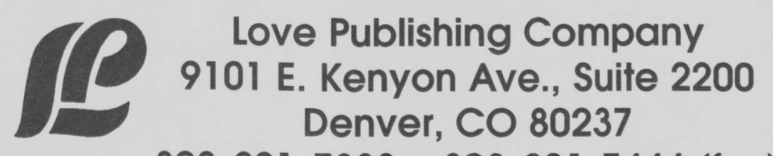

$303-221-7333 \cdot 303-221-7444$ (fax) 
limitations. Self-directed relaxation training is possible for many students with special needs.

\section{SUMMARY}

Hyperactivity and impulsivity, as well as poor attention in its various forms, are encountered much more often in atypical populations, including those with learning disabilities. Many children with disabilities display attentional difficulties or some kind of lethargic, dreamy state. These problems are amenable to treatment by physical educators who are knowledgeable and willing to apply specific techniques and methods.

Among the strategies useful in this context are the following: (a) relaxation training, in which an effort is made to reduce excess muscular tensions; (b) impulse-control activities, coupled with imagery, which encourage the child to move slowly and suppress the impulse to move inappropriately and excessively; and (c) cognitive-behavioral strategies employing movement tasks together with self-talk to reduce hyperactivity and help children manage their own thoughts more effectively.

Teachers should be aware of how a variety of conditions and factors contribute to or detract from pupils' attention. Management of the environment, specific techniques, and a teacher's own behaviors, postures, and voice combine to either heighten or reduce hyperactive, impulsive, and faulty attention behaviors in students.

\section{REFERENCES}

August, G. J., \& Stewart, M. A. (1983). Familial subtypes of childhood hyperactivity. Journal of Nervous \& Mental Disease, 171, 362-366.

Brandon, J. E., Eason, R. L., \& Smith, T. L. (1986). Behavioral relaxation training and motor performance of learning disabled children with hyperactive behaviors. Adapted Physical Activity Quarterly, 3, 67-79.

Carter, J., Lax, B., \& Russell, H. (1979). Effects of relaxation training on academic achievement of educable retarded boys. Education \& Training of the Mentally Retarded, 10, 39-41.

Carter, J., \& Russell, H. (1980). Biofeedback and academic attainment of learning disabled children. Academic Therapy, 15, 483-486.

Carter, J., \& Synolds, D. (1974). Effects of relaxation training upon handwriting quality. Journal of Hearing Disabilities, 7, 235-238.

Dunn, F. M., \& Howell, R. J. (1982). Relaxation training and its relationship to hyperactivity in boys. Journal of Clinical Psychology, 38, 92-100.

Gadow, K. D. (1983). Effects of stimulant drugs on academic performance in hyperactive and learning disabled children. Journal of Learning Disabilities, 16, 290-299.
Glantz, K. (1983). The use of relaxation exercises in the treatment of reading disability. Journal of Nervous \& Mental Disease, 171, 191-195.

Hallahan, D. P., \& Sapona, R. (1983). Self-monitoring of attention with learning disabled children: Past research and current issues. Journal of Learning Disabilities, 16, 616-620.

Herson, M., \& Barlow, D. H. (1976). Single-case experimental designs: Strategies for studying behavioral change. New York: Pergamon Press.

Jacobson, E. (1938). Progressive relaxation. Chicago: University of Chicago Press.

Jacobson, E. (1973). Teaching and learning: New methods for old arts. Chicago: National Foundation for Progressive Relaxation. (ERIC Document Reproduction Service No. ED 097-295)

Kendall, P. C., \& Finch, A. J., Jr. (1979). Developing nonimpulsive behavior in children: Cognitive-behavioral strategies for self-control. In P. C. Kendall \& S. D. Hollen (Eds.), Cognitive-behavioral interventions: Theory, research, and procedures. New York: Academic Press.

Meichenbaum, D. H., \& Goodman, L. (1969). Training impulsive children to talk about themselves: A means of developing self-control. Journal of Abnormal Psychology, 7, 533-565.

Poppen, R., \& Maurer, J. P. (1982). Electromyographic analysis of relaxed postures. Biofeedback \& Self-Regulation, 7, 491-498.

Rickard, H. C., Thrasher, K. A., \& Elkins, P. D. (1984). Responses of persons who are mentally retarded to four components of relaxation instruction. Mental Retardation, 22, 248-252.

Savelli, M. D., Cratty, B. J., \& Pistoletti, A. (1985). Relaxation training effects upon classroom attention and impulsivity in youth 11-14 years. Manuscript submitted for publication.

Schilling, D., \& Poppen, R. (1983). Behavioral relaxation training and assessment. Journal of Behavior Therapy \& Experimental Psychiatry, 14, 99-107.

Setterlind, S. (1983). Relaxation training in schools (Studies in Educational Sciences No. 43-335). Goteborg, Sweden: University of Goteborg.

Torrey, C. (1981). The effects of progressive relaxation on a motor task with hyperactive children. Paper presented at the Third International Symposium on Adapted Physical Activity, New Orleans.

Wadden, T. A. (1983). Predicting treatment response to relaxation therapy for essential hypertension. Journal of Nervous \& Mental Disease, 171, 167-174.

\section{ADDITIONAL REFERENCES}

Barkley, R. A. (1981). Hyperactive children: A handbook for diagnosis and treatment. New York: Guilford Press.

Cratty, B. J. (1986). Self-control. In B. J. Cratty, Active learning (2nd ed.) (ch. 2). Englewood Cliffs, NJ: Prentice-Hall.

Hinshaw, S. P., Henker, B., \& Whalen, C. (1984). Cognitive behavioral and pharmacological interventions for hyperactive boys: Comparative and combined effects. Journal of Consulting \& Clinical Psychology, 52, 739-749. 